\title{
Effect of Coating and Annealing on Giant Magneto Impedance in Co and Fe-Based Amorphous Wires
}

\author{
Naim Derebasi \\ Department of Physics, Bursa Uludag University, 16059 Gorukle Bursa, Turkey \\ E-mail: naim@uludag.edu.tr
}

\begin{abstract}
Effect of coating with different chemical complexes on giant magneto impedance effect (GMI) was experimentally investigated in $\mathrm{Fe}$ and $\mathrm{Co}$-based amorphous wires. The successive ionic layer adsorption and reaction (SILAR) technique was used for coating of the samples at room temperature. The SILAR method mainly based on adsorption and reaction on the ions from the solution and rinsing. Co and $\mathrm{Fe}-$ based amorphous wires were coated with $\mathrm{CoO}$, asphaltene and $\mathrm{ZnO}$ chemical complexes. The coating thickness was determined to be about $1 \mu \mathrm{m}$ thick. Maximum GMI ratio for Co and Fe-based samples were measured at $4 \mathrm{MHz}$ and $5 \mathrm{MHz}$ frequency, respectively.

Influence of annealing at different temperatures on GMI effect was also experimentally investigated in the same samples. The coated samples were annealed at $300{ }^{\circ} \mathrm{C}, 400{ }^{\circ} \mathrm{C}, 500^{\circ} \mathrm{C}$ and $600{ }^{\circ} \mathrm{C}$ temperatures in order to stress relief for 30 minutes. It is observed that the GMI ratio on Co- and Fe-based $\mathrm{ZnO}$ coated samples was highest at $500{ }^{\circ} \mathrm{C}$, while it was maximum on $\mathrm{CoO}$ coated Co-based samples at $400{ }^{\circ} \mathrm{C}$ and on $\mathrm{CoO}$ coated $\mathrm{Fe}$-based samples at $500^{\circ} \mathrm{C}$.

The highest GMI ratio among the measured samples was detected as 216 on the Fe-based, $\mathrm{ZnO}$ coated and annealed sample at $500{ }^{\circ} \mathrm{C}$ at $5 \mathrm{MHz}$, while the smallest GMI ratio, was found to be as 88 on Cobased as-cast sample at $4 \mathrm{MHz}$. The measurements show that the GMI ratio is a combined effect of coating, annealing and frequency of ac current in a static magnetic field.
\end{abstract}

Keywords Amorphous magnetic materials, SILAR technique, giant magneto impedance.

\section{Special Issue of Educational Sciences}

DOI: $10.7176 / J S T R / 6-06-03$

\section{Introduction}

GMI effect is termed as the giant variation of impedance of a ferromagnetic conductor with an ac current in an applied dc magnetic field [1]. The origin of GMI effect is related to classical effect, which refers to the fact that an applied ac current of high frequency concentrates mainly on the outer part of the magnetic material [2]. The GMI effect of Fe-based amorphous wire has attracted great attention and studied due to its important applications such as magnetic sensor and recording head. Impedance of Co and Fe-based amorphous wires changes with static magnetic field $\left(H_{d c}\right)$ [3]. This expressed in GMI\% $(\Delta Z / Z)$ is defined by the largest value of the ratio;

$$
\frac{\Delta Z}{Z} \%=\frac{Z(H)-Z\left(H_{m}\right)}{Z\left(H_{m}\right)} x 100
$$

where $H_{m}$ maximum dc applied field which is $\pm 8 \mathrm{kA} / \mathrm{m}$ produced by a solenoid as shown in Fig. 1 .

The SILAR method is relatively a novel method, first reported in 1985 by Ristov et al [4]. The SILAR technique is a suitable method for making uniform coating for Co and Fe-based amorphous wires. This method is mainly based on the absorption and reaction of the ions from the solution and rinsing between every immersion with deionised water to avoid homogeneous precipitation in the solution [5,6] shown as in Fig. 2. The method does not require high quality substrates, the deposition rate and the thickness of 
the film can be easily controlled over a wide range with changing the deposition cycles, there are virtually no restrictions on substrate material, dimensions or its surface profile; moreover, it is convenient for large amount of deposition [7].

The best conditions for the oxides $\mathrm{ZnO}, \mathrm{CoO}$, Asphaltene, coated to the sample, were 0.1 molar concentration, about $12-\mathrm{pH}$ value and at $80^{\circ} \mathrm{C}$ temperature. It was four cycles for coating as shown in Fig. 2 and the time period for coating was $8,25,25$ and 8 seconds in each coating cycle. This process was repeated 30 times to obtain desirable coating

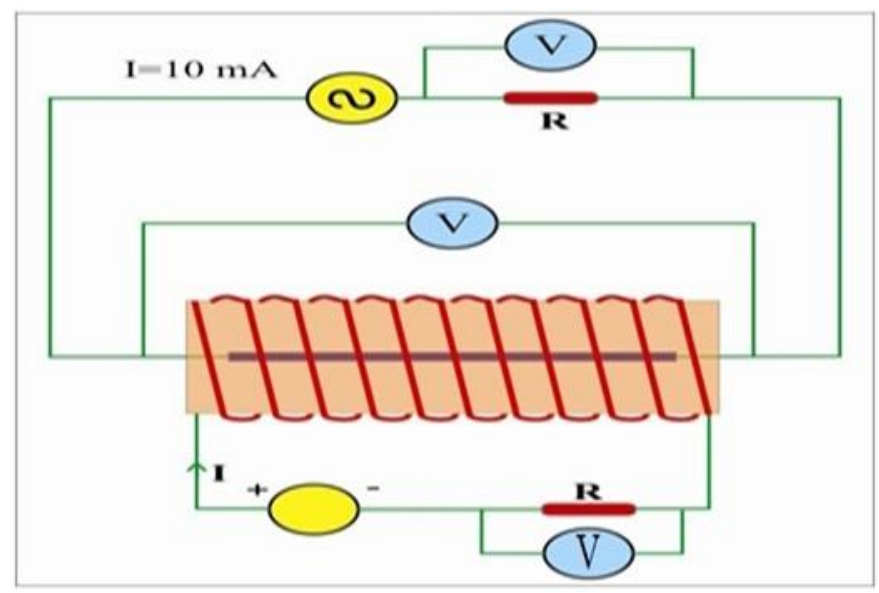

Fig. 1. Experimental schematic measuring system.

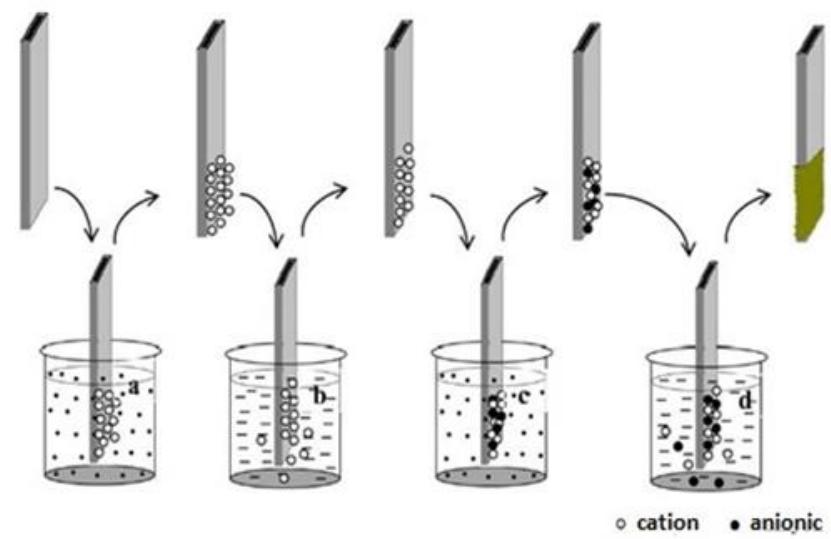

Fig. 2. Schematic diagram of SILAR method.

thickness, which is about $500 \mathrm{~nm}$. Finally, the detail characterization of surface coating like homogeneity, thickness, etc. was carried out using the AFM and SEM [3,5]. This research is concentrated on the effect of coating and annealing on the GMI effect under ac current passing thorough the near zero (AC-20) and high magnetostriction (AF-10) amorphous wires in static magnetic field.

\section{Experimental measurements}

$\mathrm{CoO}, \mathrm{ZnO}$ and asphaltene coated $\mathrm{Co}$ and Fe-based amorphous wires with the diameter $125 \mu \mathrm{m}, 120 \mu \mathrm{m}$ and $12 \mathrm{~cm}$ long were used for the GMI ratio measurements. The Co-based (AC-20) amorphous wire has a $\mathrm{Fe}_{4.3} \mathrm{Co}_{68.2} \mathrm{Si}_{12.5} \mathrm{~B}_{15}$ chemical formula and near zero magnetostriction, while Fe-based (AF-10) amorphous wire has a $\mathrm{Fe}_{77.5} \mathrm{Si}_{7.5} \mathrm{~B}_{15}$ chemical formula and $35 \times 10^{-6}$ saturation magnetostriction. A conventional setup was designed to measure the GMI ratio. The voltage drop across the sample was measured using a selective digital multimeter model HP-3458A made by Agilent Technology. An ac excitation signal was obtained from a function generator model HP-33250A in the range of 0.01-9.0 MHz. A dc axial magnetic field was produced by a long solenoid connected to a dc current source. The 
magnetic field in the solenoid was calculated using the voltage drop across a series non-inductive resistor connected to the solenoid. The ac current passing through the wire was kept constant at $10 \mathrm{~mA}$ using a commercial power amplifier during the sweep of the dc axial field while the impedance changed. The samples are carefully located and fixed in the middle of the solenoid, which the magnetic field is uniform. An air-drying silver conductive paint was used to obtain better contact between the sample ends and connection wires [8]. The optimum operation frequency was defined for all coated Co and Fe based samples and the highest GMI ratio were also defined for the $\mathrm{CoO}$ and $\mathrm{ZnO}$ coated samples. Samples were annealed at varied temperatures such as $300{ }^{\circ} \mathrm{C}, 400{ }^{\circ} \mathrm{C}, 500{ }^{\circ} \mathrm{C}$ and $600{ }^{\circ} \mathrm{C}$ respectively for stress relief and 30 minutes to understand the annealing-stress effect on the GMI ratio.

\section{Results and Discussions}

The GMI effect can be improved by measuring at a reasonable frequency that gives maximum enhancement without magnetisation. In general, the coating the sample surface with different complex thin film has improved the GMI ratio at all frequencies. However, there exists an optimum frequency, where the GMI ratio was maximum for the sample investigated. It was about 4.0 and $5.0 \mathrm{MHz}$ for $\mathrm{Co}$ based and Fe-based samples respectively, shown as in Fig. 3 and Fig. 4. The GMI ratio was measured on the Co-based near zero magnetostriction as-cast, $\mathrm{CoO}$, asphaltene and $\mathrm{ZnO}$ coated amorphous wire samples. The highest GMI ratio was detected on $\mathrm{ZnO}$ coated sample. It was about $221 \%$ as compared with as-cast uncoated sample and then, $\mathrm{CoO}$ and asphaltene coated samples were followed respectively [Fig. 3].

Maximum GMI ratio was recorded on the Fe-based $\mathrm{ZnO}$ coated and without annealed sample, it was $147 \%$ higher than as-cast sample measured and then, $\mathrm{CoO}$ and asphaltene coated samples were followed. When the GMI ratio was evaluated among the Co-based and Fe-based untreated amorphous wires, which have near zero and high magnetostriction values respectively the Fe-based (AF-10) amorphous wire has higher GMI ratio, which was $235 \%$ than the Co-based (AC-20) amorphous wire [Fig. 4]. This behavior can be attributed to intrinsic magnetic properties of the sample such as magnetic domain wall movements, magnetostriction and anisotropy of the material [1].
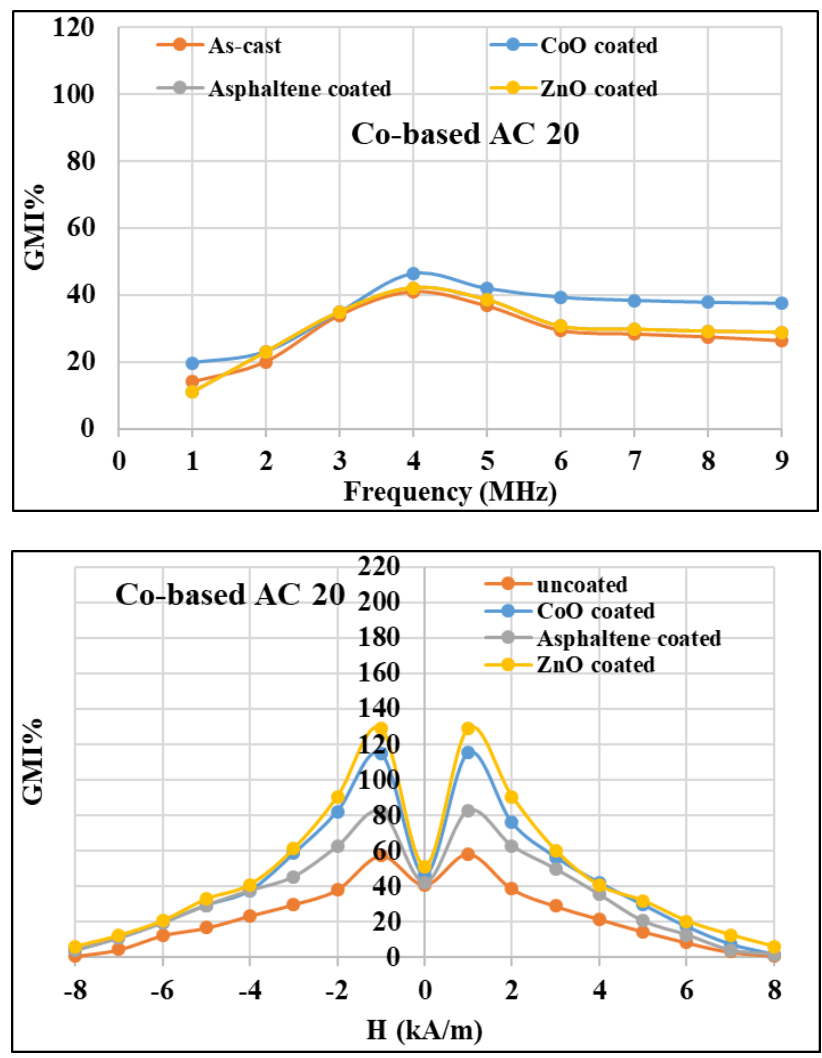

Fig. 3. Variation of GMI ratio with frequency of excitation current under constant static magnetic field (left) and magnetic field at $4 \mathrm{MHz}$ (right) for Co-based amorphous wire. 
The frequency of excitation current has much less pronounced on sensitivity of GMI ratio, while the chemical composition of sample has a significant effect, which means that the sample with high magnetostriction has high GMI ratio as compared with the sample with near zero magnetostriction. Fig. 5 shows variation of the GMI ratio with dc magnetic field on $\mathrm{CoO}$ coated Co-based and Fe-based amorphous wires at different annealing temperatures. The highest GMI\% was obtained at $400{ }^{\circ} \mathrm{C}$ for both samples. The GMI ratio was $187 \%$ higher than as-cast sample on Co-based sample, while it was $149 \%$ on Fe-based sample at $400{ }^{\circ} \mathrm{C}$ annealing temperature. However, the highest GMI ratio, which was $162 \%$ high, was measured on Fe-based sample as compared with Co-based sample.

A similar trend was obviously obtained on $\mathrm{ZnO}$ coated $\mathrm{Co}$-based and Fe-based amorphous wires at different annealing temperatures as shown Fig. 6. For these samples the GMI ratio was $134 \%$ higher than as-cast sample on Co-based sample, while it was $173 \%$ on Fe-based sample at $500{ }^{\circ} \mathrm{C}$ annealing temperature. Nevertheless, the highest GMI ratio, which was $147 \%$ high, was recorded on Fe-based sample as compared with Co-based sample.
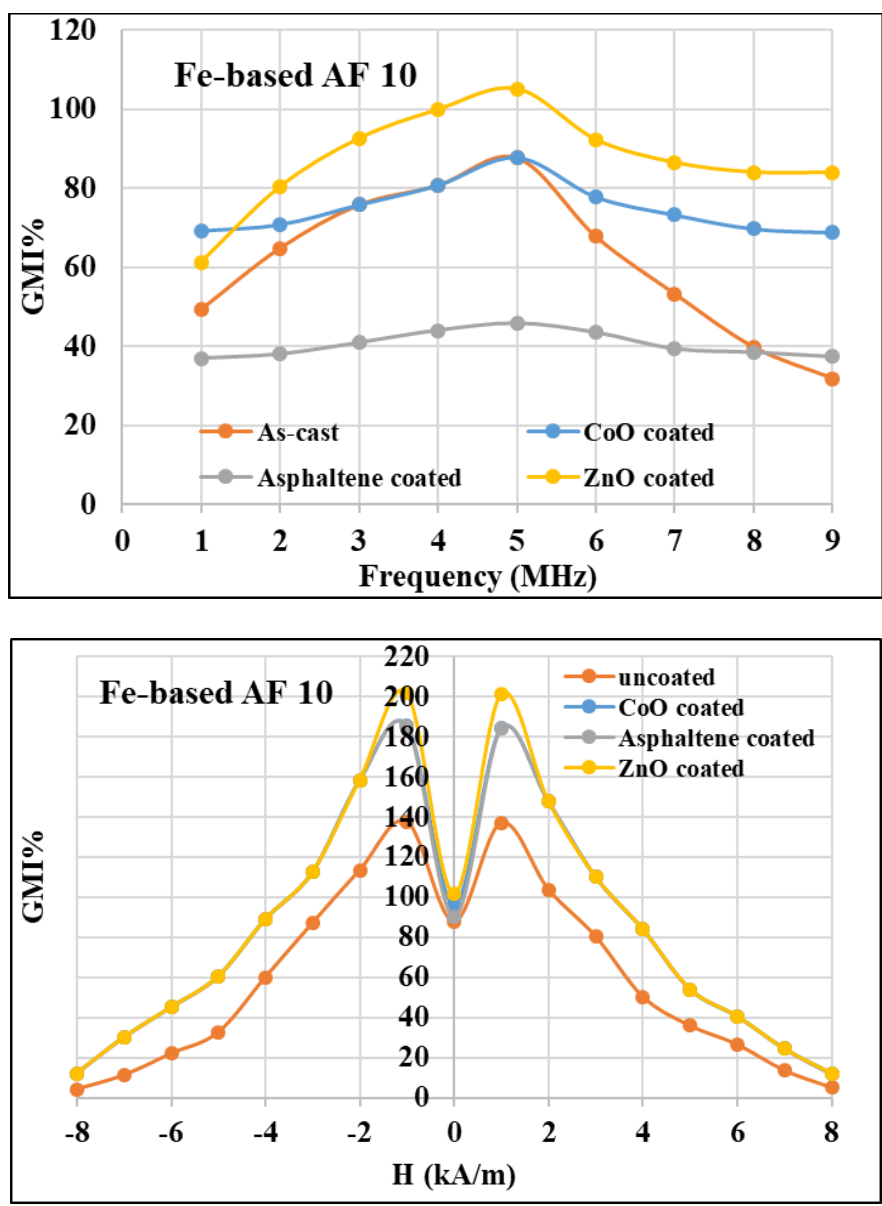

Fig. 4. Variation of GMI ratio with frequency of excitation current under constant static magnetic field (left) and magnetic field at $5 \mathrm{MHz}$ (right) for Fe-based amorphous wire. 

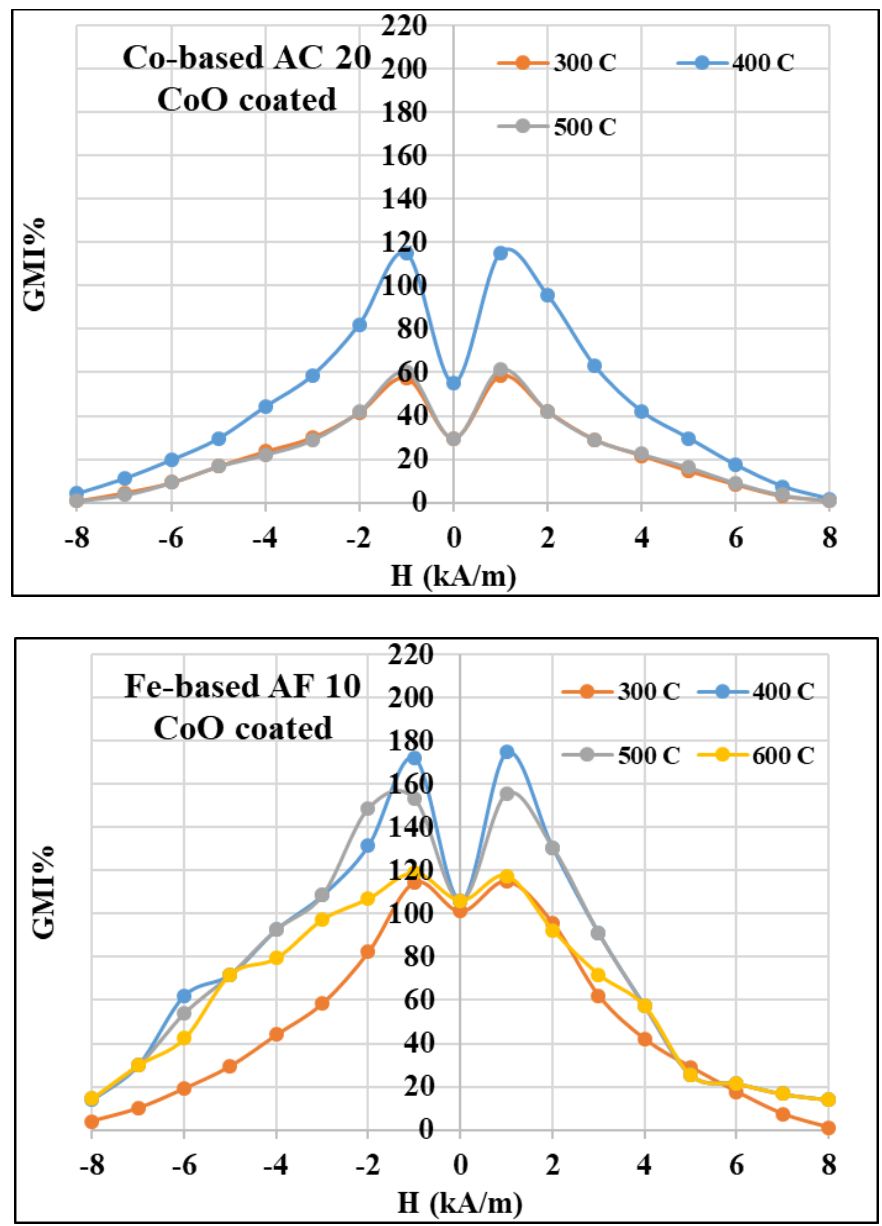

Fig. 5. Variation of GMI ratio with static magnetic field for Co-based (left) and Fe-based (right) $\mathrm{CoO}$ coated amorphous wires with different annealing temperatures.

The results show that the GMI ratio is a combined effect of coating, annealing and frequency of exciting current under static applied magnetic field. It can be attributed to the intrinsic magnetic properties of the sample such as domain wall movements, magnetostriction and anisotropy of material. It is difficult to understand clearly, which effect is more dominant on the GMI effect. However, the highest GMI ratio among the investigated samples at $5 \mathrm{MHz}$ was detected on the sample, which is the Fe-based, high magnetostriction, $\mathrm{ZnO}$ coated and annealed at $500{ }^{\circ} \mathrm{C}$, while the smallest GMI ratio was found to be on Co-based, near zero magnetostriction as-cast sample at $4 \mathrm{MHz}$.

Table 1 summarizes the measured samples and treated methods. It can be understood from the evaluation of Table 1 that the sample, which is Fe-based, high magnetostriction, $\mathrm{ZnO}$ coated and annealed at 500 ${ }^{\circ} \mathrm{C}$ measured at $5 \mathrm{MHz}$ is more sensitive to the magnetic field and suitable for defined sensors applications. 

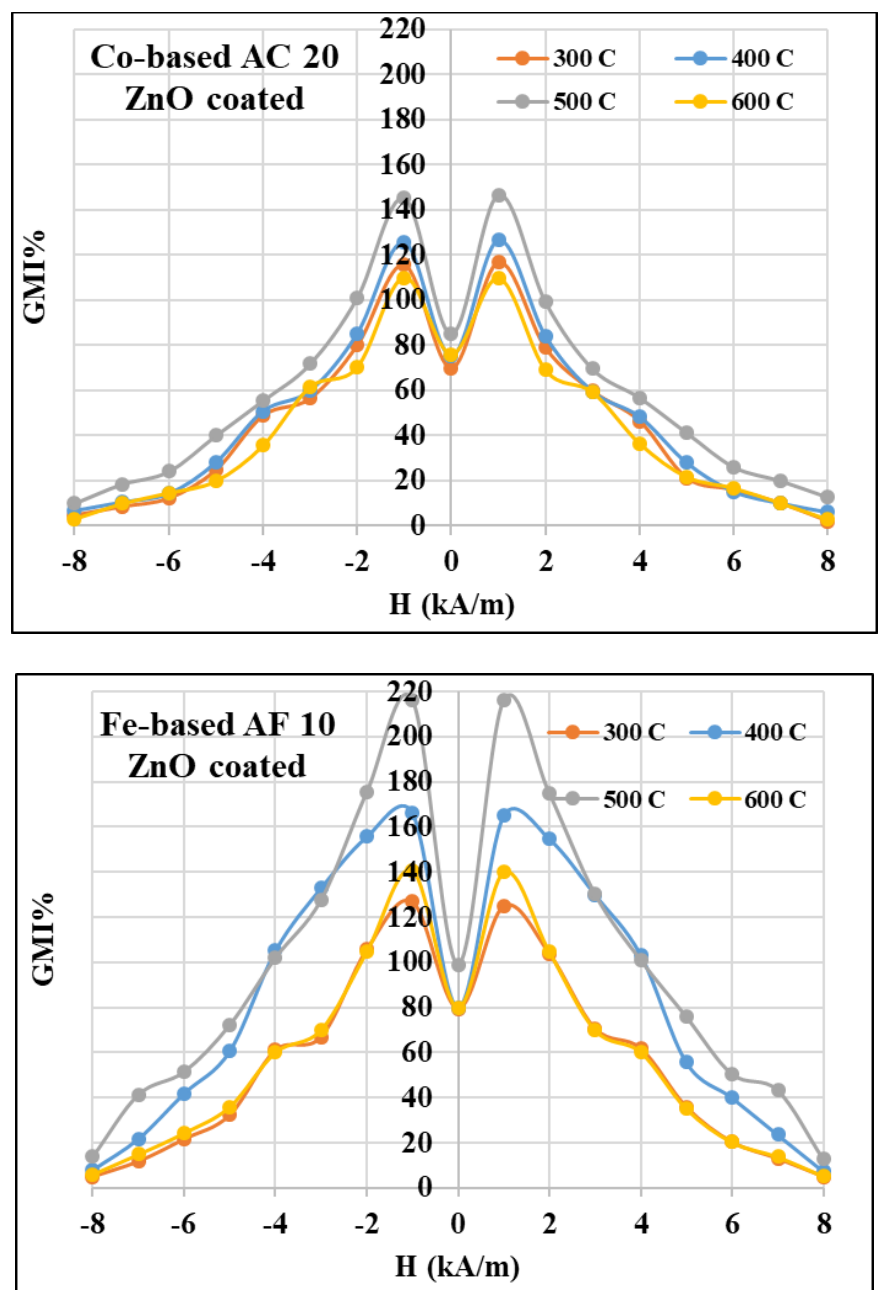

Fig. 6. Variation of GMI ratio with static magnetic field for Co-based (left) and Fe-based (right) $\mathrm{ZnO}$ coated amorphous wires with different annealing temperatures. 
Table 1. Summary of GMI \% ratios for as-cast and treated Co and Fe based samples.

\begin{tabular}{|c|c|c|c|c|c|c|}
\hline $\begin{array}{c}\text { Sample } \\
\text { No }\end{array}$ & $\begin{array}{c}\text { Chemical } \\
\text { composition }\end{array}$ & $\begin{array}{l}\text { Coating } \\
\text { material }\end{array}$ & $\begin{array}{c}\text { Operating } \\
\text { frequency } \\
(\mathrm{MHz})\end{array}$ & $\begin{array}{l}\text { Annealing } \\
\text { temperature }\end{array}$ & $\begin{array}{c}\text { Max. GMI } \\
\text { ratio (as-cast) }\end{array}$ & $\begin{array}{c}\text { GMI ratio } \\
\text { (coated) }\end{array}$ \\
\hline 1. & $\mathrm{Fe}_{4.3} \mathrm{Co}_{68.2} \mathrm{Si}_{12.5} \mathrm{~B}_{15}$ & $\begin{array}{l}\mathrm{CoO}, \mathrm{ZnO}, \\
\text { Asphaltene }\end{array}$ & 4 & No annealing & 58 & $129(\mathrm{ZnO})$ \\
\hline 2. & $\mathrm{Fe}_{77.5} \mathrm{Si}_{7.5} \mathrm{~B}_{15}$ & $\begin{array}{l}\mathrm{CoO}, \mathrm{ZnO}, \\
\text { Asphaltene }\end{array}$ & 5 & No annealing & 137 & $201(\mathrm{ZnO})$ \\
\hline 3. & $\mathrm{Fe}_{4.3} \mathrm{Co}_{68.2} \mathrm{Si}_{12.5} \mathrm{~B}_{15}$ & $\begin{array}{l}\mathrm{CoO}, \mathrm{ZnO}, \\
\text { Asphaltene }\end{array}$ & 4 & $400{ }^{\circ} \mathrm{C}$ & 58 & $145(\mathrm{ZnO})$ \\
\hline 4. & $\mathrm{Fe}_{77.5} \mathrm{Si}_{7.5} \mathrm{~B}_{15}$ & $\begin{array}{l}\mathrm{CoO}, \mathrm{ZnO}, \\
\text { Asphaltene }\end{array}$ & 5 & $400{ }^{\circ} \mathrm{C}$ & 137 & $203(\mathrm{ZnO})$ \\
\hline 5. & $\mathrm{Fe}_{4.3} \mathrm{Co}_{68.2} \mathrm{Si}_{12.5} \mathrm{~B}_{15}$ & $\mathrm{CoO}$ & 4 & $\begin{array}{c}300^{\circ} \mathrm{C}, 400{ }^{\circ} \mathrm{C} \\
500{ }^{\circ} \mathrm{C}\end{array}$ & 58 & $115\left(400^{\circ} \mathrm{C}\right)$ \\
\hline 6. & $\mathrm{Fe}_{77.5} \mathrm{Si}_{7.5} \mathrm{~B}_{15}$ & $\mathrm{CoO}$ & 5 & $\begin{array}{c}300^{\circ} \mathrm{C}, 400^{\circ} \mathrm{C}, \\
500{ }^{\circ} \mathrm{C}\end{array}$ & 137 & $175\left(400^{\circ} \mathrm{C}\right)$ \\
\hline 7. & $\mathrm{Fe}_{4.3} \mathrm{Co}_{68.2} \mathrm{Si}_{12.5} \mathrm{~B}_{15}$ & $\mathrm{ZnO}$ & 4 & $\begin{array}{l}300^{\circ} \mathrm{C}, 400^{\circ} \mathrm{C}, \\
500^{\circ} \mathrm{C}, 600^{\circ} \mathrm{C}\end{array}$ & 58 & $147\left(500^{\circ} \mathrm{C}\right)$ \\
\hline 8. & $\mathrm{Fe}_{77.5} \mathrm{Si}_{7.5} \mathrm{~B}_{15}$ & $\mathrm{ZnO}$ & 5 & $\begin{array}{l}300^{\circ} \mathrm{C}, 400^{\circ} \mathrm{C}, \\
500^{\circ} \mathrm{C}, 600^{\circ} \mathrm{C}\end{array}$ & 137 & $216\left(500^{\circ} \mathrm{C}\right)$ \\
\hline
\end{tabular}

\section{Conclusions}

The highest GMI ratio was obtained at exciting frequencies of $4 \mathrm{MHz}$ for Co-based and $5 \mathrm{MHz}$ for Febased amorphous wires. The exciting frequency is not depended on coating or annealing of the sample. The GMI effect sensitively depends on not only the post-production treated process such as coating and annealing, but also exciting frequency and applied magnetic field. This behavior can be attributed to the intrinsic magnetic properties of the sample, which are domain wall movements, magnetostriction and anisotropy. As the highest GMI ratio among the measured samples was detected on the Fe-based, high magnetostriction, $\mathrm{ZnO}$ coated and annealed at $500{ }^{\circ} \mathrm{C}$ sample, these conditions are optimum to detect sensitively the magnetic field and suitable for designing a GMI sensor at desired applications.

\section{Acknowledgment}

The author would like to thank Dr. Osman Caylak for collecting experimental data. This work was supported by Bursa Uludag University Research Grant No. BAP 2009/29. The author would also like to thank for this support.

\section{References}

[1] Panina, L.V and Mohri K. (1994), "Magneto-Impedance in Amorphous Wires, ” Appl. Phys. Lett., vol. 65(9), pp. 1189-1191.

[2] Quin F.X., Peng H.X. and M.H. Phan (2010), "Wire-lenght effect on GMI in $\mathrm{Co}_{70.3} \mathrm{Fe}_{3.7} \mathrm{~B}_{10} \mathrm{Si}_{13} \mathrm{Cr}_{3}$ amorphous glass-coated microwires," Mat. Science Eng. B, vol. 167, pp. 129-132.

[3] Caylak O., Derebasi N. and Meydan T. (2007), "Giant Magneto-Impedance Effect in As-cast and Post-production Treated $\mathrm{Fe}_{77.5} \mathrm{Si}_{7.5} \mathrm{~B}_{15}$ Amorphous Wires,” Sensor. Lett., vol. 5, pp. 123-125. 
[4] Pathan H. M. and Lokhande C. D. (2004), "Deposition of metal chalcogenide thin films by successive ionic layer adsorption and reaction (SILAR) method," Bull. of Mat. Sci., vol. 27, pp. 85-111.

[5] Taysioglu A.A., Peksoz A., Kaya Y., Derebasi N., Irez G. and Kaynak G. (2009), “GMI effect in $\mathrm{CuO}$ coated Co-based amorphous ribbons,” J. of Alloys and Comp., vol. 487, pp. 38-41.

[6] Ubale A.U., Daryapurkar A.S., Mankar R.B., Raut R.R., Sangawar V.S. and Bhosale C.H. (2008), "Electrical and optical properties of $\mathrm{Bi}_{2} \mathrm{~S}_{3}$ thin films deposited by successive ionic layer adsorption and reaction (SILAR) method," Mater. Chem. Phys., vol. 110, pp. 180-185.

[7] More A.M., Gunjakar J.L., Lokhande C.D. and Joo O.S.(2009), “C. J. Kaufman,” Fabrication of hydrophobic surface titanium dioxide films by successive ionic layer adsorption and reaction (SILAR) method," Appl. Surf. Sci., vol. 255, pp. 182-187.

[8] Caylak O. and Derebasi N. (2008), , "Prediction of giant magneto impedance on as-cast and post production treated $\mathrm{Fe}_{77.5} \mathrm{Si}_{7.5} \mathrm{~B}_{15}$ amorphous wires using neural network, J. of Opt. and Adv Mater., vol. 10(11), pp. 2916-2918. 